\title{
Nonsteroidal Anti-Inflammatory Drug Reduces Neutrophil and Macrophage Accumulation but Does Not Improve Tendon Regeneration
}

\author{
David Marsolais, Claude H. Côté, and Jérôme Frenette \\ Department of Rehabilitation, Faculty of Medicine, (DM, CHC, JF), Université Laval, Quebec, Canada
}

\begin{abstract}
SUMMARY: Whether nonsteroidal anti-inflammatory drugs have a beneficial effect on tendon regeneration is still a matter of debate. Given that inflammatory cells are thought to induce nonspecific damage following an injury, we tested the hypothesis that a 3-day treatment with diclofenac would protect tendons from inflammatory cell injury and would promote healing. Neutrophil and $\mathrm{ED}^{+}$macrophage concentrations were determined in the paratenon and the core of the rat Achilles tendon following collagenase-induced injury. Hydroxyproline content, edema, and mechanical properties were also evaluated at 1, 3, 7, 14, and 28 days post-trauma. Collagenase injections induced a $70 \%$ decrease in the ultimate rupture point at Day 3 . Diclofenac treatments $(1 \mathrm{mg} / \mathrm{kg} \mathrm{bid})$ selectively decreased the accumulation of neutrophils and ED1 $1^{+}$macrophages by $59 \%$ and $35 \%$, respectively, in the paratenon, where blood vessels are numerous, but did not reduce the accumulation of neutrophils and ED1 ${ }^{+}$ macrophages in the core of the tendon. Edema was significantly reduced on Day 3 but persisted during the remodeling phase in the diclofenac-treated group only. The inhibition of leukocyte accumulation by diclofenac did not translate into a reduction of tissue damage or a promotion of tissue healing, because the mechanical properties of injured Achilles tendons were identical in placebo and diclofenac-treated groups. These results indicate that diclofenac reduced both edema and the accumulation of inflammatory cells within the paratenon but provided no biochemical or functional benefits for the Achilles tendon. (Lab Invest 2003, 83:991-999).
\end{abstract}

\begin{abstract}
$N$ onsteroidal anti-inflammatory drugs (NSAIDs) are widely prescribed to reduce pain and inflammation following soft tissue injuries. NSAIDs inhibit tissue inflammation by repressing cyclooxygenase (COX) activity, thereby leading to a reduction in proinflammatory prostaglandin synthesis (Vane, 1996). NSAIDs can also repress inflammation by inducing apoptosis (Shiff et al, 1995), activating peroxisome proliferator-activated receptors- $\alpha$ and $-\gamma$ (Lehmann et al, 1997) and inhibiting neutrophil (PMN) aggregation (Cronstein et al, 1994) and degranulation (Kaplan et al, 1984). Diclofenac can induce shedding of adhesion molecules located on PMNs, thereby inhibiting their locomotion and ability to invade inflamed tissues (Diaz-Gonzalez et al, 1995; Perianin et al, 1985). Because prostaglandins can play an important role in the accumulation of inflammatory cells in many tissues and leukocyte subsets may exacerbate tissue injuries, it is believed that reducing $\mathrm{PGE}_{2}$ production and inflammatory cell accumulation using COX inhibitors will lead to a reduction in tendon injury. However, the effects of NSAIDs on connective tissue repair have produced diverging and contradictory results. For
\end{abstract}

\section{DOI: 10.1097/01.LAB.0000078688.07696.AC}

Received January 7, 2003.

Support provided by the Natural Sciences and Engineering Research Council of Canada and the Fonds de la Recherche en Santé du Québec.

Address reprint requests to: Dr. Jérôme Frenette, CHUL Research Center, 2705 Boulevard Laurier, Room-9500, Sainte-Foy, Quebec, Canada G1V 4G2.E-mail:Jerome.Frenette@crchul.ulaval.ca example, the administration of a nonspecific inhibitor of COX activity increases ligament strength by $42 \%$ at 14 days postsurgical transection, whereas a specific COX-2 inhibitor decreases ligament strength as compared with a placebo (Dahners et al, 1988; Elder et al, 2001). Although the conclusions of these studies are weakened by the fact that no specific inflammatory cell markers were employed to verify the efficacy of the NSAIDs, the observations are consistent with the current view that inflammatory cells participate in both the degenerating and regenerating processes at sites of injury (Cowin et al, 2001; Lapointe et al, 2002b; Li et al, 2001).

We recently showed in a rat model of tendon injury that different populations of inflammatory cells, such as PMNs, $\mathrm{ED}^{+}{ }^{+}$, and $\mathrm{ED} 2^{+}$macrophages $(\mathrm{M} \phi \mathrm{s})$, accumulate sequentially (Marsolais et al, 2001). PMNs accumulate rapidly at injury sites, where they can increase extracellular matrix damage through the release of proteases and potentially delay tissue regeneration (Palmgren et al, 1992). PMN invasion is followed by $M \phi$ accumulation 1 to 3 days post-injury. These cells play key roles in the early phase of wound healing and are likely very important for effective wound debridement (Frisen et al, 1993), angiogenesis (Swift et al, 1999), fibroblast activity, and subsequent collagen synthesis (Khalil et al, 1989). The use of NSAIDs may thus both repress the catabolic actions of inflammation and alleviate important signals for tissue regeneration. We hypothesized that a 3-day treatment with diclofenac during the highly catabolic 
phase of inflammation would protect tendons from injury and promote tissue healing. In this study, we assessed inflammatory cell accumulation, edema, hydroxyproline content, and mechanical properties of Achilles tendons at $1,3,7,14$, and 28 days postcollagenase injury. These time points encompass the periods of inflammatory cell accumulation, collagen degradation, and initiation of the regeneration process (Marsolais et al, 2001). The results demonstrate that diclofenac decreased the accumulation of inflammatory cells during the acute phase of inflammation but neither prevented tissue damage nor accelerated the healing process.

\section{Results}

\section{Concentration of Inflammatory Cells and Blood Vessels in the Paratenon and the Core of the Achilles Tendon}

Collagen fibers are well organized and have a parallel orientation in normal Achilles tendons (Fig. 1A). Collagenase injection induced tissue disorganization, as shown by the large pink areas in Masson's trichromestained sections (Fig. 1B). The histologic appearance of the Achilles tendon was identical in both experimental groups 28 days post-recovery, but the collagen fibers remained small and disorganized (Fig. 1, C to D). To verify whether diclofenac can modify the accumulation of inflammatory cells, PMNs and ED1 ${ }^{+}$ $M \phi s$ were immunolabeled on longitudinal sections of Achilles tendon (Fig. 1, $\mathrm{E}$ to $\mathrm{H}$ ). The sequence of inflammatory cell accumulation was similar to previous observations in tendons and skeletal muscles (Frenette et al, 2002; Marsolais et al, 2001). Immunolabeling with the PECAM antibody showed that blood vessels are highly concentrated in the paratenon (Fig. $1 \mathrm{~J})$. Relative to the ambulatory controls, the sham procedure induced a small but significant increase in the concentrations of ED1 ${ }^{+} \mathrm{M} \phi s$ and PMNs up to Days 3 and 7, respectively (Figs. 2 and 3). Collagenase injections increased the concentrations of PMNs by 450-fold and ED1 ${ }^{+} \mathrm{M} \phi$ s by 15-fold compared with the control at Day 1 post-trauma in the paratenon of the Achilles tendon (Figs. 2A and 3A). PMNs and ED1 ${ }^{+}$ $\mathrm{M} \phi \mathrm{s}$ disappeared gradually and returned to sham values at Days 14 and 28, respectively. The administration of diclofenac reduced the accumulation of PMNs by $59 \%$ and $\mathrm{ED} 1^{+} \mathrm{M} \phi$ s by $35 \%$ relative to the placebo in the paratenon at Day 1 post-trauma, indicating that diclofenac efficiently blocked leukocyte accumulation.

In contrast, the diclofenac treatment had no effect on the accumulation of PMNs and ED1 ${ }^{+} \mathrm{M} \phi \mathrm{s}$ in the core of the Achilles tendon at Days 1, 3, 7, and 14 post-trauma. As observed with the paratenon, the concentrations of $\mathrm{ED} 1^{+} \mathrm{M} \phi \mathrm{s}$ in the cores of Achilles tendons treated with diclofenac also failed to return to sham values on Day 28. The concentrations of ED2 ${ }^{+}$ $\mathrm{M} \phi \mathrm{s}$ did not increase significantly over time in either placebo or diclofenac-treated animals compared with sham values (unpublished data). Because diclofenac is transported through the circulatory system, we decided to verify whether differences in blood vessel concentrations could explain the specific effect of diclofenac in the paratenon. Quantitative analysis revealed that the density of blood vessels was 12 times higher in the paratenon than in the core of the Achilles tendon (Fig. 4).

\section{Edema Formation, Hydroxyproline Content, and Biomechanical Properties}

Water content, which was quantified to determine whether diclofenac influenced edema formation, was approximately $59 \mathrm{ml} / 100 \mathrm{~g}$ of wet mass in control tendons and increased by $30 \%$ at Day 3 post-trauma in the placebo group (Fig. 5A). The administration of diclofenac reduced edema by approximately $35 \%$ at Day 3 relative to the placebo. The water content decreased steadily in placebo-treated groups between Days 3 and 14. In contrast, edema failed to diminish between these two time points in the diclofenac-treated rats, suggesting that the resolution of the inflammatory phase was retarded following the administration of the NSAID.

To assess collagen content, hydroxyproline was measured in placebo and diclofenac-treated animals. As expected, collagenase injections induced a significant reduction in collagen content in both the placebo and diclofenac groups (Fig. 5B). The lowest concentrations of hydroxyproline were recorded at Days 3 and 7 postcollagenase injection in the placebo and diclofenac groups, respectively. The hydroxyproline content gradually increased after Day 7 but failed to reach the control value after 28 days in both experimental groups. The functional integrity of the tendons was also tested in a separate set of experiments. Tendons were stretched to measure stiffness and the ultimate rupture point to determine whether NSAID treatment influenced mechanical properties. Control values for the ultimate rupture point and maximal stiffness were $85.7 \mathrm{~N}$ and $86.1 \mathrm{~N} / \mathrm{mm}$, respectively (Fig. 6, A and B). Following collagenase injection, both the ultimate rupture point and stiffness dropped by approximately $70 \%$ on Day 3 in the placebo group. Subsequently, the ultimate rupture point and stiffness of injured tendons recovered progressively to reach $48 \%$ and $51 \%$ of control values, respectively, at the end of the protocol. Thus, the mechanical properties of the injured tendons remained significantly different from control values at the end of the protocol. Treatment with NSAIDs had no significant impact on the mechanical properties of the Achilles tendon at all time points tested. Lastly, we verified whether a relationship could be observed between the ultimate rupture point and hydroxyproline content. Interestingly, hydroxyproline content strongly correlated with the capacity of the Achilles tendon to sustain mechanical stress in all groups tested, suggesting that hydroxyproline content may be a good indicator of tendon function (Fig. 7). 

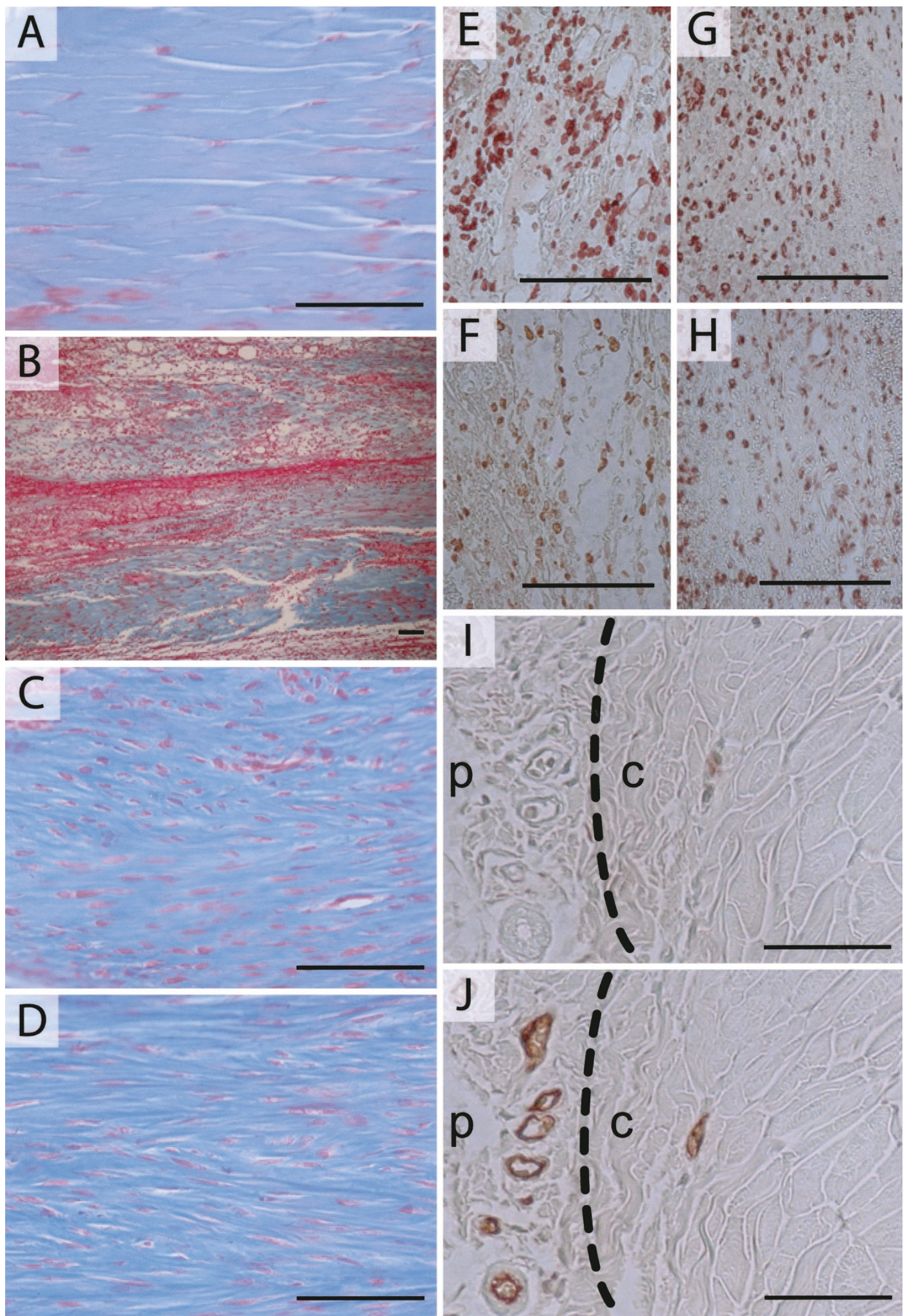

\section{Figure 1.}

Histologic and immunohistochemical assessments of injured and control Achilles tendons. Masson's trichrome staining, which colors collagen blue and other proteins pink, was performed on longitudinal sections of uninjured tendon (A), placebo tendon 1 day postcollagenase injection (B), and placebo (C) and diclofenac-treated tendons (D) 28 days postcollagenase injection. Immunolabeling of neutrophils (PMNs) was performed on peripheral sections of injured placebo (E) and diclofenac-treated (F) tendons 1 day post-trauma. Immunolabeling of ED1 ${ }^{+}$macrophages $(\mathrm{M} \phi \mathrm{s})$ on peripheral sections of injured placebo $(\mathrm{G})$ and diclofenac-treated $(\mathrm{H})$ tendons 1 day post-trauma showing that diclofenac reduces the number of inflammatory cells in the paratenon. PMNs and ED1+ M $\phi S$ were not labeled when primary antibodies were omitted. Immunolabeling of blood vessels was performed on cross-sections of control Achilles tendons. Cross-sections of Achilles tendons labeled without $(\mathrm{I})$ and with PECAM antibody $(\mathrm{J})$ showing that blood vessels are highly concentrated in the paratenon $(p)$ and widely dispersed in the core $(c)$. The dashed line separates the paratenon from the core. Bars $=75 \mu \mathrm{m}$. 
PARATENON
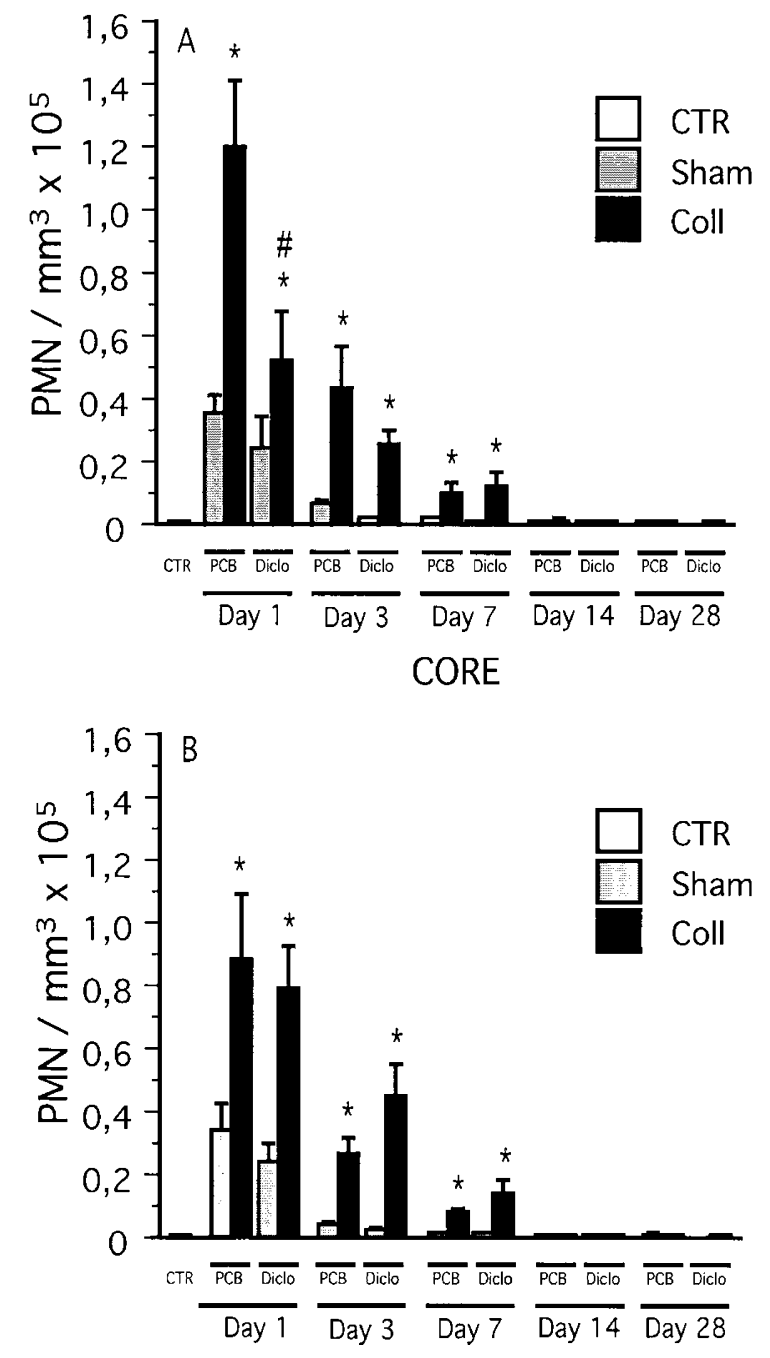

Figure 2.

Concentrations of neutrophils (PMNs) in Achilles tendons from placebo (PCB) and diclofenac-treated (Diclo) animals. PMN concentrations are shown in the paratenon $(A)$ and core of the Achilles tendon $(B)$. Data are means \pm standard errors of the means from five to six experiments, $p<0.05$. *Significantly different from matched sham; \#significantly different from placebo.

\section{Discussion}

Tendons heal very slowly through the formation of scar tissue following chemical, physical, or mechanical injuries and rarely regain their original strength. In general, the sequence and time course of events that occur during tendon healing closely resemble those reported in many other tissues. Different subpopulations of leukocytes rapidly invade the inflamed tissue to phagocyte cellular debris and stimulate fibroblast proliferation and collagen deposition (Gelberman et al, 1991). Interestingly, the number and type of inflammatory cells recruited at injured sites may play an important role in the degree of scarring and the quality of the healing response. For example, the number and persistence of different subsets of leukocytes are lower following dermal injuries in fetal tissues than in adult tissues. Lower leukocyte accumulation in fetal wounds

\section{PARATENON}
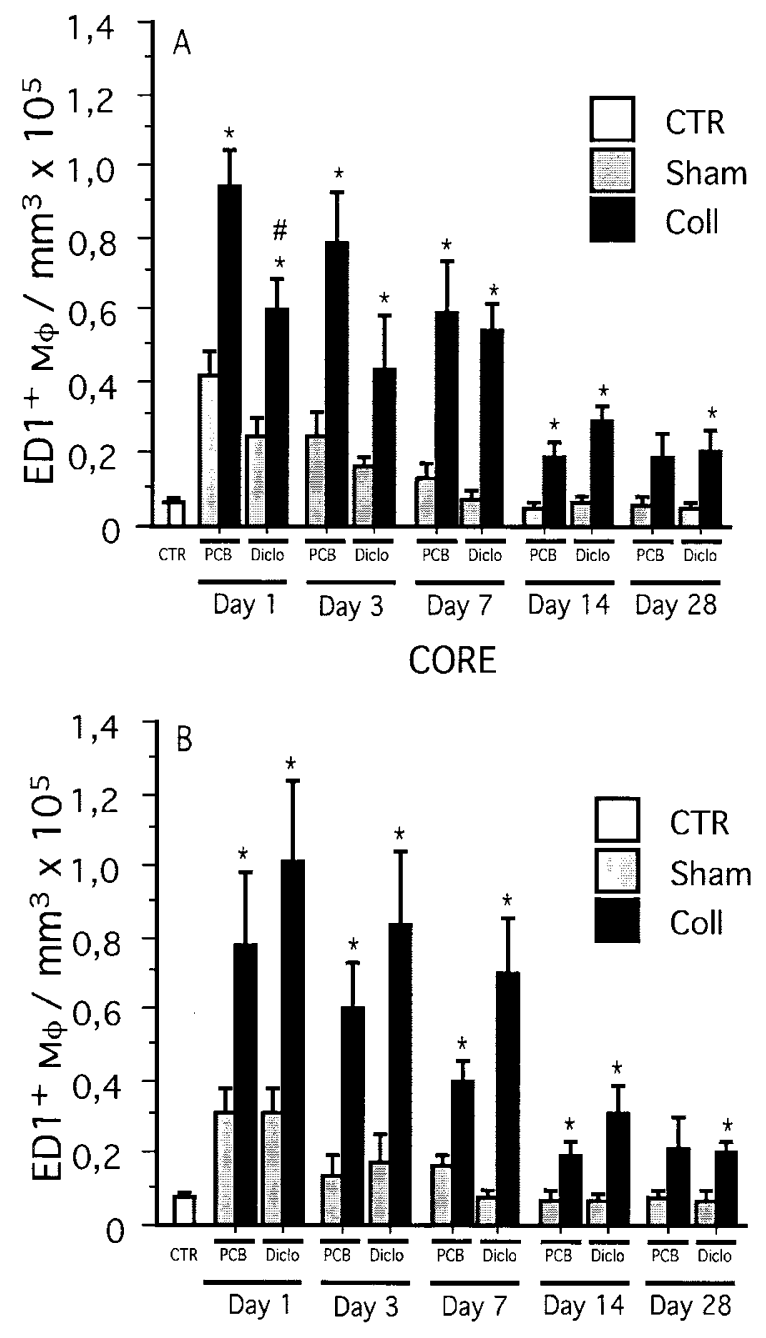

Figure 3.

Concentrations of ED1 ${ }^{+}$macrophages $(M \phi s)$ in Achilles tendons from placebo $(\mathrm{PCB})$ and diclofenac-treated (Diclo) animals. ED1 ${ }^{+} \mathrm{M} \phi$ concentrations are shown in the paratenon $(A)$ and core of the Achilles tendon (B). Data are means \pm standard errors of the means from five to eight experiments, $p<0.05$. *Significantly different from matched sham; \#significantly different from placebo.

results in a scar-free phenotype not observed in adult tissues (Adolph et al, 1993; Cowin et al, 1998). The teleological arguments for the use of NSAIDs on a regular basis in clinical practice are thus strongly based on the reduction or modulation of the number of inflammatory cells at wound sites, which may eventually diminish tissue injury and scar formation.

Even though the history of NSAIDs stretches back through the use of willow bark extracts, the effect of NSAIDs on final healing outcome remain a topic of much debate. Previous investigations have demonstrated that NSAIDs may impair (Almekinders and Gilbert, 1986; Elder et al, 2001), have no effect on (Minns and Muckle, 1982; Thomas et al, 1991), or enhance (Dahners et al, 1988; Obremsky et al, 1994) tissue healing. The findings presented here clearly show that diclofenac did not change the functional 


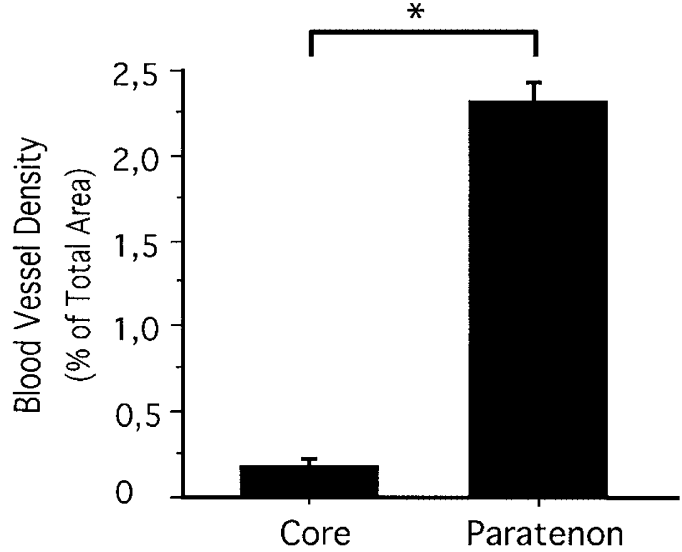

Figure 4.

Quantification of blood vessel density in the core and the paratenon of control Achilles tendons. Immunolabeling was performed as described in "Materials and Methods." Labeled areas are expressed as percentages of sampled areas from the paratenon and core area. Data are means \pm standard errors of the means from six experiments. *Significantly different, $p<0.001$.
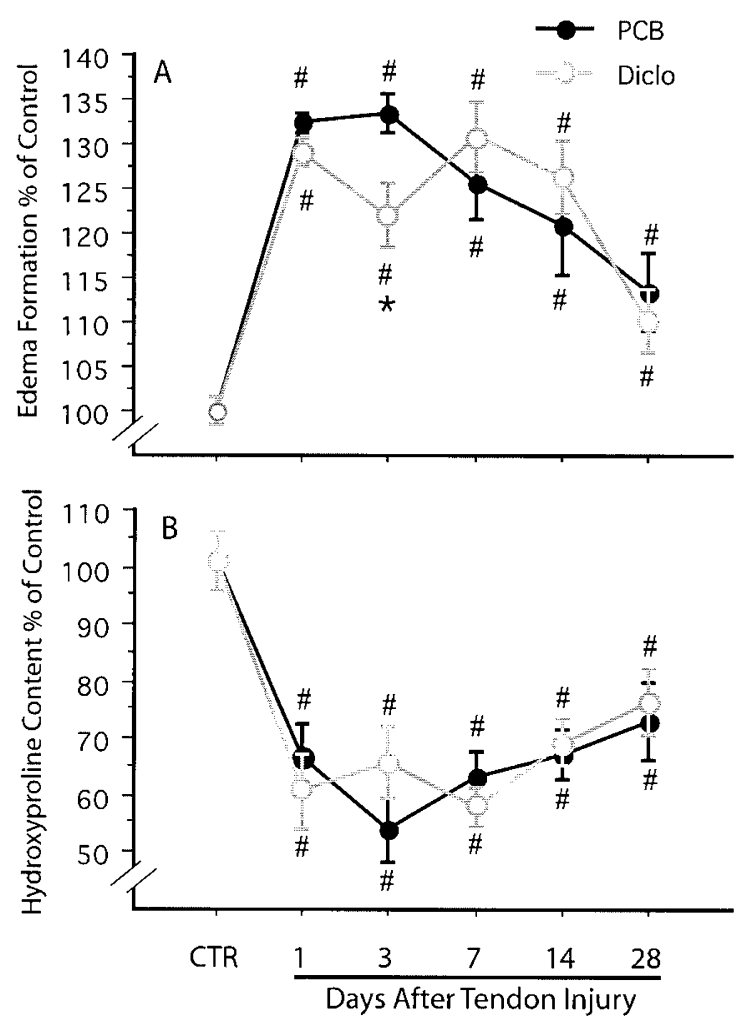

Figure 5.

Hydroxyproline concentration and edema formation in injured Achilles tendons. Hydroxyproline concentrations $(A)$ and edema formation $(B)$ are shown in control animals $1,3,7,14$, and 28 days postcollagenase injection. Values are expressed as percentages of controls. Data are means \pm standard errors of the means from seven to nine experiments, $p<0.05$. *Significantly different from placebo.

properties of the healing tendon. Our results also demonstrate that diclofenac preferentially modulated the accumulation of PMNs and $\mathrm{ED} 1^{+} \mathrm{M} \phi \mathrm{s}$ in the paratenon. Possible explanations for this unexpected finding include the following: (a) The bioavailability of diclofenac was only sufficient to inhibit leukocyte
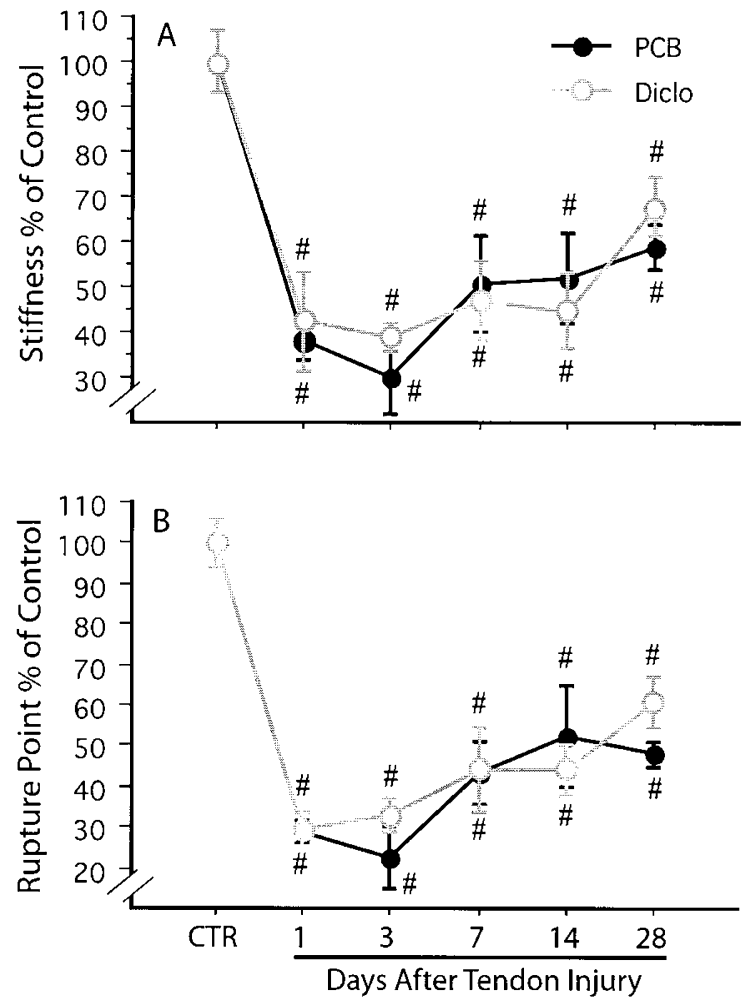

Figure 6.

Mechanical properties of injured Achilles tendons. Stiffness (A) and ultimate rupture point (B) are shown in control animals $1,3,7,14$, and 28 days postcollagenase injection. All points are different from control animals. Data are means \pm standard errors of the means from five to eight experiments, $p$ $<0.05$.

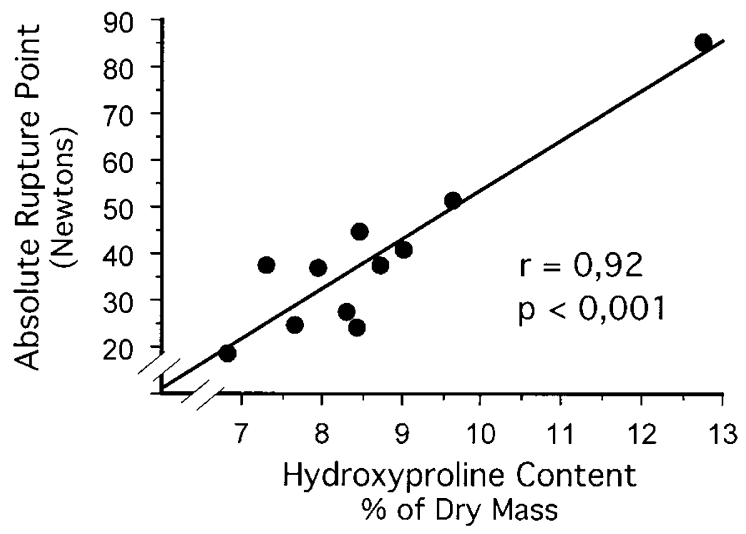

Figure 7.

Relationship between hydroxyproline content and ultimate rupture points of Achilles tendons. Mean values of hydroxyproline content and ultimate rupture points for placebo and diclofenac-treated animals were analyzed using simple regression analysis. The ultimate rupture point increased linearly with hydroxyproline content. $r=0.92 ; p<0.001$.

recruitment in the paratenon where the vascular system is well developed, and the available concentration of diclofenac was probably below the effective dose in the core of the tendon, which is the hypovascularized region of the Achilles tendon; (b) prostaglandins might be synthesized rapidly in the paratenon following tissue injury and may exert chemoattraction locally and promote leukocyte recruitment (Langberg et al, 
1999); (c) The presence of diclofenac could induce L-selectin shedding, which may impair leukocyte rolling and recruitment; such action would predominantly occur where blood vessels are abundant (DiazGonzalez et al, 1995); and (d) The use of diclofenac might inhibit the enzymatic degradation of lipoxins, biologically active eicosanoids that can decrease PMN recruitment via chemokine down-regulation, reduce PMN degranulation and stimulate the uptake of apoptotic PMNs by M $\phi$ s (Clish et al, 2001). However, the presence of lipoxins at higher concentrations in the paratenon relative to the core of the tendon has not been documented. The hypovascular network in the core of Achilles tendon may explain the lack of effect of diclofenac in this region.

The results presented here also constitute a highly valuable addition for the characterization of collagenase-induced tendon injury. Our values for hydroxyproline content in control rats are in agreement with previous results published for tendons and other similar connective tissues (Takacs and Verzar, 1968; Vailas et al, 1985, 1988). Although long term monitoring for hydroxyproline content during tendon degeneration and regeneration has never been clearly reported, we showed that the rapid loss of hydroxyproline coincides with the accumulation of PMNs and $M \phi s$, which supports the hypothesis that leukocytes phagocytose and digest collagen during the inflammatory phase. The finding that the concentration of hydroxyproline gradually increased also supports similar observations that extensive collagen synthesis begins after 7 days (Garner et al, 1989). The appearance of $\mathrm{M} \phi \mathrm{s}$ is most likely necessary for the initiation and formation of new tissue because $\mathrm{M} \phi$ depleted animals have defective wound repair mechanisms and $\mathrm{M} \phi$ implantation accelerates tissue healing (Danon et al, 1989). Many cytokines secreted by M $\phi$ s can accelerate wound healing, the formation of granulation tissue, and the deposition of extracellular matrix. Transforming growth factor- $\beta 1$ would be the most likely candidate for orchestrating wound repair in that it can stimulate both fibroblast proliferation and collagen production (Cordeiro et al, 2000; Kinbara et al, 2002).

The biomechanical properties of rat Achilles tendon observed in our study compare favorably with those reported in the literature, but our technical procedures minimized slippage during stretching, which increased the ultimate rupture points relative to previous study (Almeida-Silveira et al, 2000). The present findings also clearly demonstrated that regenerating processes in Achilles tendon are remarkably slow because mechanical functions reached only $50 \%$ to $60 \%$ of control values after 28 days. Although total recovery following an Achilles tendon injury may require almost 1 year, the compelling histologic, biochemical, and mechanical data obtained with respect to the inflammation and repair phases indicated that diclofenac does not have any beneficial effects on tendon repair. These observations are consistent with the view that diclofenac has no effect on PMN accumulation in collagen bundles, the most important collagenic struc- tures that transmit large loads following muscle contractions. The presence of PMNs can cause collagen damage through the release of metalloproteases and free radicals (Zhu et al, 2001). The lack of effect of NSAIDs in collagen bundles is particularly relevant because many forms of tendinitis in humans and horses occur in the tensile region of the tendon (Archambault et al, 1995). In addition, our findings that edema and the presence of ED1 ${ }^{+} \mathrm{M} \phi$ s seem to persist in diclofenac-treated rats reinforce the current view that NSAIDs can prolong the inflammatory process. For example, Gilroy et al (Gilroy et al, 1999) used a model of carrageenin-induced pleurisy to demonstrate that NSAIDs retard the resolution of inflammation. It was recently shown that a delay in the disappearance of ED1 ${ }^{+} \mathrm{M} \phi \mathrm{s}$ occurred following diclofenac treatment in a model of exercise-induced muscle damage (Lapointe et al, 2002a). Another recent study clearly demonstrated that specific inhibition of COX-2 activity by NS-398 or nonspecific inhibition of COX activity by indomethacin causes a significant delay in wound healing in rat skin (Futagami et al, 2002). In contrast, the addition of $\mathrm{PGE}_{2}$-stimulated wound closure in airway epithelium (Savla et al, 2001). Together, these findings suggest that COX-dependent metabolites play a role in stimulating wound healing in various tissues.

In summary, data obtained with the present model of tendon injury support the conclusions that treatment with diclofenac does not prevent collagen degradation and loss of tensile force at the onset of tendon injury. It is therefore questionable whether NSAIDs should be used to alleviate inflammation in acute tendon injuries. Further investigations using direct approaches are needed to determine the roles played by each inflammatory cell subset in tendon repair. Lastly, we speculate that the slow rate of tendon healing may be due to an insufficient number of cells activating fibroblast or secretory fibroblasts involved in tendon fabrication. Testing of strategies designed to promote migration and activation of fibroblasts to influence tendon healing and function might be a promising approach to resolve this question.

\section{Materials and Methods}

\section{Experimental Procedures}

Collagenase-induced tendon injury has been previously characterized in our laboratory and described in detail (Marsolais et al, 2001). Female Wistar rats (180 to $200 \mathrm{~g}$ ) allowed normal cage activity were used. The rats were anesthetized by intraperitoneal injection of a ketamine/xylazine cocktail $(87.5 \mathrm{mg} / \mathrm{kg}$ and $12.5 \mathrm{mg} /$ $\mathrm{kg}$, respectively). Instruments were sterilized to avoid local inflammation due to infection. The Achilles tendons of both hindlimbs were exposed by a slight incision above the osteotendinous junction. For immunolabeling analyses, the experimental tendon was injected with $30 \mu \mathrm{l}$ of crude collagenase solution (5 $\mathrm{mg} / \mathrm{ml}$; Sigma, St. Louis, Michigan) using a 30-gauge needle. Collagenase was dissolved in sterile PBS 
(PBS). Contralateral Achilles tendons were injected with the same volume of vehicle and used as sham groups. In another series of experiments where mechanical testing was performed, both Achilles tendons were injected with $30 \mu \mathrm{l}$ of the $5 \mathrm{mg} / \mathrm{ml}$ collagenase solution. Injury was induced in both tendons to evaluate hydroxyproline and water content as well as the mechanical properties of injured tendons on the same animal. Mechanical data from injured tendons were thus compared with tendons originating from control rats, but the sham procedure did not induce any functional deficit (unpublished data). The incision was closed with sutures and gently washed with a topical antiseptic solution. Following the surgical procedures, the animals were rehydrated by injecting $5 \mathrm{ml}$ of Ringer's lactate subcutaneously and then placed under a heat lamp to prevent hypothermia until awakening.

\section{Drug Administration}

The animals were randomly divided into two groups. Six hours following collagenase injection, the time needed to recover completely from anesthesia, the placebo and experimental groups were gavaged with water or diclofenac dissolved in water at $1 \mathrm{mg} / \mathrm{kg}$. All animals were treated bid for six doses. The rats were killed 1, 3, 7, 14, and 28 days postcollagenase injection. Ambulatory control rats were killed without prior intervention or after the administration of six doses of diclofenac administered bid.

\section{Immunohistochemistry}

To label inflammatory cells, hindlimbs were removed immediately after death. The foot was positioned in a dorsiflexion position, and the whole limb was fixed overnight in $10 \%$ formalin at $4^{\circ} \mathrm{C}$. Achilles tendons were then excised between the osteotendinous and myotendinous junctions, dehydrated in increasing concentrations of alcohol, and cleared in three changes of xylene. After dehydration and clearing on ice, Achilles tendons were embedded overnight in paraffin at $60^{\circ} \mathrm{C}$ and the paraffin blocks stored at $-20^{\circ} \mathrm{C}$. Sections from the paratenon and core of each tendon were systematically selected at 0.25 and 0.75 $\mathrm{mm}$ from the lateral edge of the tendon, respectively. Longitudinal sections were labeled for the PMNs and $\mathrm{ED}^{+} \mathrm{M} \phi \mathrm{s}$ as previously described (Marsolais et al, 2001).

To label blood vessels, uninjured tendons were excised and fixed for 3 days in a zinc solution $(0.5 \%$ zinc acetate and $0.5 \% \mathrm{ZnCl}_{2}$ in $0.1 \mathrm{M}$ Tris base buffer containing $0.05 \%$ calcium acetate) (Beckstead, 1994). Tendons were embedded in paraffin and transversally cut at a thickness of $5 \mu \mathrm{m}$. Tissue sections from two distinct regions of the tendon were collected in duplicate. Tendons were quenched with a solution of $3 \%$ hydrogen peroxide diluted in methanol to abrogate endogenous peroxidase activity. Nonspecific sites were blocked for 20 minutes in a solution containing $100 \mathrm{~mm}$ Tris, $150 \mathrm{~mm} \mathrm{NaCl}, 150 \mathrm{~mm}$ sodium azide,
$0.5 \%$ Tween $20,0.2 \%$ gelatin, and $3 \%$ BSA. Sections were then overlaid without the primary antibody or incubated overnight at $4^{\circ} \mathrm{C}$ with antirat CD31 antibody (BD Pharmingen, California), which binds to an adhesion molecule commonly called PECAM-1 located in the endothelium of blood vessels. All sections were then washed with PBS and incubated with biotinylated antimouse Ig G antibody (1:200; Vector Laboratories, Burlingame, California) for 60 minutes. Tissue samples were washed with PBS and incubated with horseradish peroxidase (1:1000; Vector Laboratories) before revealing the antibody-antigen complex by chromogenic development using DAB peroxidase substrate kit (Dako Diagnostics Canada Inc., Ontario, Canada). Transverse sections were then viewed under a Nikon inverted microscope equipped with a Cool Snap photometrics CCD camera. Blood vessel density was quantified by using Metamorph image software. Following acquisition, images were converted from pixels to micrometers using a calibration image. The color threshold was set to include labeled blood vessels with minimal unspecific background. Three sample areas were selected in the paratenon and the core of the tendon, and the surface areas occupied by blood vessels were expressed as percentages of total areas.

\section{Mechanical Testing}

In another set of experiments, Achilles tendons were excised with the calcaneum and the inferior portions of the gactrocnemius, plantaris, and soleus muscles. Samples were placed in a humid chamber on PBSmoistened gauze to avoid drying and swelling (Wang and Ker, 1995). Muscle tissue was gently removed from the tendons, and both extremities were rapidly wiped and glued between two pieces of balsa wood with Loctite 495. Achilles tendons were then fixed in metal jaws covered with \#40 sandpaper and connected to the load cell of a MTS 858 Mini Bionix II device (MTS Systems Corporation, Eden Prairie, Minnesota). Initial length was manually set at a tension of 1 to $2 \mathrm{~N}$. The test, conducted with Model 793.00 System Software, version 3.2 (MTS Systems Corporation), was performed to obtain a tension-elongation curve using a strain rate of $10 \%$ of initial length per second until rupture. Tension (Newtons) and elongation $(\mathrm{mm})$ were monitored at a frequency of $10 \mathrm{~Hz}$. Tension-elongation curves were plotted and discarded if slippage or absence of a clear rupture point was noted. Stiffness was defined as the maximal slope of the linear portion of the tension-elongation curve in a time lapse of 0.5 second. Ultimate rupture force was also recorded.

\section{Measurements of Edema and Hydroxyproline Content}

Once the biomechanical properties had been measured, the left Achilles tendons were dehydrated for 24 hours at $60^{\circ} \mathrm{C}$ (Takacs and Verzar, 1968), and the ratio ([wet mass to dry mass]/wet mass) was used to obtain an index of the water content. After dehydration, 
tendons were then hydrolyzed in $6 \mathrm{~N} \mathrm{HCl}$ at $130^{\circ} \mathrm{C}$ for 3 hours, neutralized with $\mathrm{NaOH}$, and diluted in water. The extracts were used for the determination of hydroxyproline content by the method of Woessner (1961).

\section{Statistical Analysis}

Fisher PLSD was used to compare means when a significant $F$ ratio was obtained following the ANOVA. Pearson correlate analysis was used to assess the relationship between ultimate rupture point and hydroxyproline content. The level of significance was set at $p<0.05$. All results are presented as means \pm standard errors of the means.

\section{References}

Adolph VR, DiSanto SK, Bleacher JC, Dillon PW, and Krummel TM (1993). The potential role of the lymphocyte in fetal wound healing. J Pediatr Surg 28:1316-1320.

Almeida-Silveira MI, Lambertz D, Perot C, and Goubel F (2000). Changes in stiffness induced by hindlimb suspension in rat Achilles tendon. Eur J Appl Physiol 81:252-257.

Almekinders LC and Gilbert JA (1986). Healing of experimental muscle strains and the effects of nonsteroidal antiinflammatory medication. Am J Sports Med 14:303-308.

Archambault JM, Wiley JP, and Bray RC (1995). Exercise loading of tendons and the development of overuse injuries: A review of current literature Sports Med 20:77-89.

Beckstead JH (1994). A simple technique for preservation of fixation-sensitive antigens in paraffin-embedded tissues. J Histochem Cytochem 42:1127-1134.

Clish CB, Sun YP, and Serhan CN (2001). Identification of dual cyclooxygenase-eicosanoid oxidoreductase inhibitors: NSAIDs that inhibit PG-LX reductase/LTB(4) dehydrogenase. Biochem Biophys Res Commun 288:868-874.

Cordeiro MF, Bhattacharya SS, Schultz GS, and Khaw PT (2000). TGF-beta1, -beta2, and -beta3 in vitro: Biphasic effects on Tenon's fibroblast contraction, proliferation, and migration. Invest Ophthalmol Vis Sci 41:756-763.

Cowin AJ, Brosnan MP, Holmes TM, and Ferguson MW (1998). Endogenous inflammatory response to dermal wound healing in the fetal and adult mouse. Dev Dyn 212:385-393.

Cowin AJ, Kallincos N, Hatzirodos N, Robertson JG, Pickering KJ, Couper J, and Belford DA (2001). Hepatocyte growth factor and macrophage-stimulating protein are upregulated during excisional wound repair in rats. Cell Tissue Res 306:239-250.

Cronstein BN, van de Stouwe M, Druska L, Levin RI, and Weissmann $G$ (1994). Nonsteroidal anti-inflammatory agents inhibit stimulated neutrophil adhesion to endothelium: Adenosine dependent and independent mechanisms. Inflammation 18:323-335.

Dahners LE, Gilbert JA, Lester GE, Taft TN, and Payne LZ (1988). The effect of a nonsteroidal anti-inflammatory drug on the healing of ligaments. Am J Sports Med 16:641-646.

Danon D, Kowatch MA, and Roth GS (1989). Promotion of wound repair in old mice by local injection of macrophages. Proc Natl Acad Sci USA 86:2018-2020.
Diaz-Gonzalez F, Gonzalez-Alvaro I, Campanero MR, Mollinedo F, del Pozo MA, Munoz C, Pivel JP, and SanchezMadrid $F$ (1995). Prevention of in vitro neutrophil-endothelial attachment through shedding of L-selectin by nonsteroidal antiinflammatory drugs. J Clin Invest 95:1756-1765.

Elder CL, Dahners LE, and Weinhold PS (2001). A cyclooxygenase-2 inhibitor impairs ligament healing in the rat. Am J Sports Med 29:801-805.

Frenette J, St-Pierre M, Cote CH, Mylona E, and Pizza FX (2002). Muscle impairment occurs rapidly and precedes inflammatory cell accumulation after mechanical loading. Am J Physiol Regul Integr Comp Physiol 282:R351-357.

Frisen J, Risling M, and Fried K (1993). Distribution and axonal relations of macrophages in a neuroma. Neuroscience 55:1003-1013.

Futagami A, Ishizaki M, Fukuda Y, Kawana S, and Yamanaka $N$ (2002). Wound healing involves induction of cyclooxygenase-2 expression in rat skin. Lab Invest 82: 1503-1513.

Garner WL, McDonald JA, Koo M, Kuhn C 3rd, and Weeks PM (1989). Identification of the collagen-producing cells in healing flexor tendons. Plast Reconstr Surg 83:875-879.

Gelberman RH, Siegel DB, Woo SL, Amiel D, Takai S, and Lee D (1991). Healing of digital flexor tendons: Importance of the interval from injury to repair: A biomechanical, biochemical, and morphological study in dogs $\mathrm{J}$ Bone Joint Surg Am 73:66-75.

Gilroy DW, Colville-Nash PR, Willis D, Chivers J, Paul-Clark MJ, and Willoughby DA (1999). Inducible cyclooxygenase may have anti-inflammatory properties. Nat Med 5:698-701.

Kaplan HB, Edelson HS, Korchak HM, Given WP, Abramson S, and Weissmann G (1984). Effects of non-steroidal antiinflammatory agents on human neutrophil functions in vitro and in vivo. Biochem Pharmacol 33:371-378.

Khalil N, Bereznay O, Sporn M, and Greenberg AH (1989). Macrophage production of transforming growth factor beta and fibroblast collagen synthesis in chronic pulmonary inflammation. J Exp Med 170:727-737.

Kinbara T, Shirasaki F, Kawara S, Inagaki Y, de Crombrugghe $\mathrm{B}$, and Takehara K (2002). Transforming growth factor-beta isoforms differently stimulate proalpha2 (I) collagen gene expression during wound healing process in transgenic mice. J Cell Physiol 190:375-381.

Langberg $\mathrm{H}$, Skovgaard D, Karamouzis M, Bulow J, and Kjaer M (1999). Metabolism and inflammatory mediators in the peritendinous space measured by microdialysis during intermittent isometric exercise in humans. J Physiol 515(Pt 3):919-927.

Lapointe BM, Frémont $\mathrm{P}$, and Côté $\mathrm{CH}$ (2002a). Adaptation to lengthening contractions is independent of voluntary muscle recruitment but relies on inflammation. Am J Physiol Regul Integr Comp Physiol 282:R323-329.

Lapointe BM, Frenette J, and Côté CH (2002b). Lengthening contraction-induced inflammation is linked to secondary damage but devoid of neutrophil invasion. J Appl Physiol 92:1995-2004.

Lehmann JM, Lenhard JM, Oliver BB, Ringold GM, and Kliewer SA (1997). Peroxisome proliferator-activated receptors alpha and gamma are activated by indomethacin and other non-steroidal anti-inflammatory drugs. J Biol Chem 272:3406-3410. 
Li M, Carpio DF, Zheng Y, Bruzzo P, Singh V, Ouaaz F, Medzhitov RM, and Beg AA (2001). An essential role of the NF-kappa B/Toll-like receptor pathway in induction of inflammatory and tissue-repair gene expression by necrotic cells. J Immunol 166:7128-7135.

Marsolais D, Côté CH, and Frenette J (2001). Neutrophils and macrophages accumulate sequentially following Achilles tendon injury. J Orthop Res 19:1203-1209.

Minns RJ and Muckle DS (1982). Mechanical properties of traumatized rat tendo-achilles and the effect of an antiinflammatory drug on the repair properties. J Biomech 15: 783-787.

Obremsky WT, Seaber AV, Ribbeck BM, and Garrett WE, Jr. (1994). Biomechanical and histologic assessment of a controlled muscle strain injury treated with piroxicam. Am J Sports Med 22:558-561.

Palmgren MS, deShazo RD, Carter RM, Zimny ML, and Shah SV (1992). Mechanisms of neutrophil damage to human alveolar extracellular matrix: the role of serine and metalloproteases. J Allergy Clin Immunol 89:905-915.

Perianin A, Gougerot-Pocidalo MA, Giroud JP, and Hakim J (1985). Diclofenac sodium, a negative chemokinetic factor for neutrophil locomotion. Biochem Pharmacol 34:3433-3438.

Savla U, Appel HJ, Sporn PH, and Waters CM (2001). Prostaglandin E(2) regulates wound closure in airway epithelium. Am J Physiol Lung Cell Mol Physiol 280:L421-431.

Shiff SJ, Qiao L, Tsai LL, and Rigas B (1995). Sulindac sulfide, an aspirin-like compound, inhibits proliferation, causes cell cycle quiescence, and induces apoptosis in HT-29 colon adenocarcinoma cells. J Clin Invest 96:491-503.
Swift ME, Kleinman HK, and DiPietro LA (1999). Impaired wound repair and delayed angiogenesis in aged mice. Lab Invest 79:1479-1487.

Takacs I and Verzar F (1968). Macromolecular aging of collagen: II The role of water content, solubility and swelling capacity of tendon fibers during aging and storage Gerontologia 14:24-34.

Thomas J, Taylor D, Crowell R, and Assor D (1991). The effect of indomethacin on Achilles tendon healing in rabbits. Clin Orthop 272:308-311.

Vailas AC, Deluna DM, Lewis LL, Curwin SL, Roy RR, and Alford EK (1988). Adaptation of bone and tendon to prolonged hindlimb suspension in rats. J Appl Physiol 65:373376.

Vailas AC, Pedrini VA, Pedrini-Mille A, and Holloszy JO (1985). Patellar tendon matrix changes associated with aging and voluntary exercise. J Appl Physiol 58:1572-1576.

Vane JR (1996). Introduction: Mechanism of action of NSAIDs (Suppl 1). Br J Rheumatol 35:1-3.

Wang XT and Ker RF (1995). Creep rupture of wallaby tail tendons. J Exp Biol 198:831-845.

Woessner JF (1961). The determination of hydroxyproline in tissue and protein samples containing small proportions of this imino acid. Arch Biochem Biophys 93:440-447.

Zhu Y, Liu X, Skold CM, Wang H, Kohyama T, Wen FQ, Ertl RF, and Rennard SI (2001). Collaborative interactions between neutrophil elastase and metalloproteinases in extracellular matrix degradation in three-dimensional collagen gels. Respir Res 2:300-305. 